\title{
ORDEM NA PRAÇA: NORMAS E EXERCÍCIO DE ADMINISTRAÇÃO EM MERCADOS DO RIO DE JANEIRO*
}

\section{ORDEN EN LA PLAZA: LAS NORMAS Y LA GESTIÓN DE ADMINISTRACIÓN DE LOS MERCADOS EN RÍO DE JANEIRO}

\section{ORDER IN THE MARKET SQUARE: ADMINISTRATION STANDARDS AND PRACTICE IN RIO DE JANEIRO'S MARKETS}

\section{L'ORDRE SUR LA PLACE DU MARCHÉ : NORMES ET PRATIQUES ADMINISTRATIVES SUR LES MARCHES DE RIO DE JANEIRO}

DOI: $10.5533 / 1984-2503-20124103$

\author{
Laura Antunes Maciel ${ }^{1}$ \\ Vitor Leandro de Souza ${ }^{2}$
}

\section{RESUMO}

Neste trabalho buscamos apresentar alguns aspectos da regulamentação e administração do comércio popular de alimentos nas Praças de Mercado do Rio de Janeiro na virada do século XIX para o XX. Procuramos, também, evidenciar a diversidade de grupos e práticas sociais envolvidos com esse comércio, assim como as tensões e embates que opuseram administradores, comerciantes e trabalhadores nos dois maiores mercados da cidade.

Palavras-chave: mercados, comércio de alimentos, cidade, regulamentos, tensões sociais.

\section{RESUMEN}

En este trabajo buscamos presentar aspectos de la reglamentación y de la administración del comercio popular de alimentos en las Plazas de Mercado de Río de Janeiro en el

\footnotetext{
*Este texto é uma versão revista e ampliada de parte de Monografia de Conclusão de Curso de Graduação em História de Vitor Leandro de Souza, intitulada "ORDEM NA PRAÇA: Ação Municipal nas Praças de Mercado do Rio de Janeiro nos séculos XIX e XX", concluída em julho de 2011 na Universidade Federal Fluminense, sob a orientação da Prof ${ }^{a}$ Laura Antunes Maciel.

${ }_{1}^{1}$ Professora Associada I da Universidade Federal Fluminense, com atuação na graduação e na pós-graduação. É tutora do Programa de Educação Tutorial em História/Conexão de Saberes na UFF. E-mail: lauramaciel@uol.com.br

${ }^{2}$ Graduado em História pela Universidade Federal Fluminense, com orientação de Laura Antunes Maciel. E-mail: vitorleandro@if.uff.br
} 
pasaje del siglo XIX al XX. Buscamos también evidenciar la diversidad de grupos y de prácticas sociales involucrados en este comercio, así como las tensiones y los enfrentamientos que opusieron administradores, comerciantes y trabajadores en los dos más grandes mercados de la ciudad.

Palabras-clave: mercados, comercio de alimentos, ciudad, reglamentos, tensiones sociales.

\section{ABSTRACT}

In this study we have sought to present features of regulations and administration concerning popular food trade in market squares across Rio de Janeiro at the turn of the $20^{\text {th }}$ century. We have also striven to prove the diversity of social groups and practices pertaining to this trade, as well as tensions and conflicts between administrators, retailers and workers in the city's two largest markets.

Key words: markets, food trade, city, regulations, social tensions.

\section{RÉSUMÉ}

Nous chercherons ici à présenter quelques-uns des aspects de la réglementation et de l'administration du commerce populaire d'alimentation sur les places de marché de Rio de Janeiro au tournant $d u X X^{e ̀ m e}$ siècle. Nous avons également voulu mettre en évidence la diversité des groupes sociaux et de leurs pratiques au sein de ce commerce, mais aussi les tensions et les conflits qui opposèrent administrateurs, commerçants et travailleurs sur les deux plus grands marchés de la ville.

Mots-clés : marchés, commerce alimentaire, ville, règlements, tensions sociales.

\section{A cidade e seus mercados}

A região atualmente denominada Praça XV foi, desde meados do século XVII, um tradicional ponto de comércio de alimentos na cidade do Rio de Janeiro, inicialmente conhecido por mercado da Praia do Peixe, pois ali estavam instalados pequenos vendedores de pescado, quitandeiras e negras de tabuleiro. Esse comércio, segundo o memorialista Nelson Costa, funcionava em bancas de forma "desorganizada", sem possuir um "alinhamento ou simetria definidos", similar a uma espécie de "feira

\footnotetext{
${ }^{3}$ Costa, Nelson (1958). Rio de Ontem e de Hoje, Rio de Janeiro: Leo, p. 211.
} 
permanente"," dotado de intensidade e colorido que impressionava os viajantes estrangeiros que aportavam na cidade.

Relatos e imagens de vários viajantes e artistas retrataram a intensidade desse comércio no século XIX, destacando algumas de suas características. O pintor e viajante inglês Charles Martin mostra, entre 1848-50, que a tradição comercial das negras minas mantinha-se forte deste lado do Atlântico ${ }^{5}$. Os franceses Jean Baptiste Debret e Felix Taunay, ambos integrantes da Missão Artística Francesa na Corte Imperial, apresentam outro dado importante, as relações sociais que se constituíam nas praças de mercado: lugar de trabalho para muitos, mas, também, de lazer, distração e descanso para trabalhadores nas pausas do trabalho. Taunay, por exemplo, retrata em uma de suas aquarelas o movimento na Rua Direita, a principal da Cidade, destacando o seu colorido comércio, marcado pela presença de carregadores, negros, quitandeiros e "senhores da sociedade", no desenrolar das negociações, nas conversas, ou seja, relacionando-se ${ }^{6}$.

Em fins do século XIX diversos cronistas, jornalistas e fotógrafos, registraram suas impressões sobre o cotidiano da cidade e nos ajudam a compreender o modo como esse comércio era realizado - em pequenas bancas, tabuleiros ou bacias -; assim como os relatos de alguns comerciantes: as pretas minas ${ }^{7}$ com seus turbantes, panos da Costa e tabuleiros, homens e mulheres pobres, "pescadores e marítimos em geral "." Apesar de alguns testemunhos indicarem que esse comércio de alimentos estava por todos os lados, "nas praias e nos largos ou apregoavam os bufarinheiros pelas ruas os legumes, cereais, aves, hortaliças, frutos e outros gêneros",", outros identificaram e associaram determinados pedaços da cidade a essas práticas: o Cais das Marinhas, a Praia Dom Manuel e o Paço - "nas proximidades da casa dos vice-reis "10".

Desde 1789, pelo menos, há registros de tentativas de "ordenar" o comércio de alimentos, quando o vice-rei Luiz de Vasconcellos decidiu a reconstrução de barracas de peixe próximas instaladas no Largo do Palácio atendendo a padrões de "regularidade e

\footnotetext{
${ }^{4}$ Farias, Juliana Barreto (2010). "Mercado em greve: Protesto e organização dos trabalhadores do pequeno comércio no Rio de Janeiro - Outubro, 1885". Anais da Biblioteca Nacional, v. 127, p. 102.

${ }^{5}$ Martin, Charles (1848). Quitandeiras do Largo do Paço. (óleo sobre tela, cor). Acervo do Museu Imperial, Petrópolis/RJ.

${ }^{6}$ Debret, Jean Baptiste (1827). Os refrescos do Largo do Palácio (aquarela sobre papel) e Negra tatuada vendendo caju. (Aquarela sobre papel); e Taunay, Felix Émile (1823). Rua Direita (aquarela sobre papel) Acervo Coleção Brasiliana/Fundação Estudar. Pinacoteca de São Paulo/SP.

7 "por volta de 1875, o fotógrafo Marc Ferrez registrou vendedoras negras" tanto no mercado quanto nos seus arredores, incluindo o cais das Marinhas. Por ocasião da greve de 1885 elas ainda chamavam a atenção dos editores do jornal O Mequetrefe. Ver: Farias, J. B. (2010). Op. cit., p. 138.

${ }^{8}$ Costa, N. (1958). Op. cit., p. 211.

9 Azevedo, Moreira de (1877). Rio de Janeiro: sua história, monumentos, homens notáveis, usos e curiosidades, V. 2. Rio de Janeiro: B. L. Garnier, p. 319.

${ }^{10}$ Azevedo, M. (1877). Op. cit., p. 481.
} 
simetria" ${ }^{11}$, tentando impedir que o número de vendedores nessa parte da cidade se expandisse cada vez mais, sem um controle efetivo da Câmara. Ainda assim, essa tentativa de reordenar o intenso comércio, não foi suficiente para conter o "tumulto" provocado pelos frequentadores do mercado.

Diante de reclamações e acusações contra os vendedores que estariam perturbando "com a sua vozeria os trabalhos ${ }^{12 " ~ d o ~ S e n a d o ~ d a ~ C a ̂ m a r a, ~ J o s e ́ ~ B o n i f a ́ c i o ~ d e ~ A n d r a d a ~ e ~}$ Silva, a pedido do Imperador, ordenou em 1823 a mudança das barracas da calçada do Largo do Paço para outro lugar. No entanto, somente em 1834 teve inicio a construção da "primeira Praça de comércio que teve o Rio de Janeiro 13", seguindo projeto arquitetônico assinado por Grandjean de Montigny ${ }^{14}$. Essa iniciativa "a pedido da municipalidade, para substituir o mercado do peixe que se realizava a céu aberto ${ }^{15}$ ", ocorreu com a intenção de colocar ordem no comércio da Freguesia da Candelária, ali instalado há pelo menos um século.

Com a conclusão das obras em 1841 o edifício estava pronto para servir a cidade e ficou conhecido como "Praça do Mercado", "Mercado da Praia do Peixe" e "Mercado da Candelária"16. Ocupando todo o quarteirão, o mercado estava dividido "em três partes, sendo destinado: o centro, para verduras, aves e ovos; o lado do mar, para peixe fresco e salgado; e o lado da rua, para cereais, legumes, farinha e cebolas ${ }^{17 ” . ~ C o n s t r u i ́ d o ~ e ~}$ instalado às margens da baía de Guanabara, a Praça do Mercado recebia através da doca contigua ao edifício "os gêneros da roça e pescado que escravos e outros trabalhadores traziam em canoas de ganho, saveiros, faluas e barcos vindos de Guaratiba, Pedra, Sepetiba ${ }^{18 ” . ~ A ~ t r a n q u i l i d a d e ~ d a s ~ a ́ g u a s ~ f l u m i n e n s e s ~ g a r a n t i a ~ a g i l i d a d e ~}$ ao transporte dos gêneros mais perecíveis, como as verduras, legumes e carnes verdes ${ }^{19}$.

O Mercado da Candelária também recebia gêneros produzidos nos "sertões" que margeavam a Guanabara como São Gonçalo, Niterói, Itamby, Magé; além de "café,

\footnotetext{
${ }^{11}$ Fridman, Sergio A. \& Gorberg, Samuel (2003). Mercados no Rio de Janeiro. 1834-1962, Rio de Janeiro: S. Gorberg, p. 2.

12 AGCRJ, Ofício da Secretaria de Estado de Negócios para o Senado da Câmara de 21/04/1823. Apud: Fridman, Sergio A. \& Gorberg, Samuel (2003). Op. cit., p. 2.

${ }_{13}^{13}$ Azevedo. M. (1877). Op. cit., p.186.

14 lbidem, p. 95.

${ }^{15}$ Benchimol, Jaime Larry (1990). Pereira Passos: um Haussmann tropical. A renovação urbana da cidade do Rio de Janeiro no início do século $X X$, Rio de Janeiro: Secretaria Municipal de Cultura, Turismo e Esportes, p.38.

${ }_{17}^{16}$ Fridman, S. A. \& Gorberg, S. (2003). Op. cit., p.12-13.

17 Almanak Laemmert (1844). Almanak Administrativo Mercantil e Industrial do Império do Brazi,. Rio de Janeiro. p. 239.

${ }_{18}$ Farias, J. B. (2010). Op. cit., p. 102.

19 Sampaio, Antonio Carlos Jucá de (1994). Magé na crise do escravismo. Sistema agrário e evolução econômica na produção de alimentos (1850-1888), Dissertação (Mestrado em História) - Instituto de Ciências Humanas e Filosofia, Universidade Federal Fluminense, Niterói, p. 18-42.
} 
tabaco, algodão, toucinho e outros víveres", que vinham de diversas regiões suburbanas da cidade; transportados por vias terrestres através de carros de boi e carroças e por um grande número de "negros, a transportarem por toda a cidade leite, frutas, legumes e flores" 20 .

O mercado era administrado e fiscalizado pela Prefeitura através do Fiscal da freguesia da Candelária. Os intendentes organizaram um Regulamento para o mercado, aprovado em 1844, que estabeleceu que as 114 bancas poderiam ser alugadas semestralmente com pagamentos antecipados, definindo a obrigatoriedade dos locatários serem "pessoas livres e capazes" ${ }^{21}$. Outras Praças de Mercados funcionaram na cidade no mesmo período e eram administrados de forma semelhante. Na região da Gamboa funcionava o Mercado da Harmonia, cedido ao General Lazaro José Gonçalves Junior, desde sua inauguração, em 28 de janeiro de 1857, para exploração e usufruto por 20 anos. O contrato firmado em 1854 entre a Câmara e o empresário determinou que o edifício fosse construído com base no projeto adotado pela municipalidade, as obras teriam início um mês após a assinatura do contrato e a conclusão das mesmas em dois anos, terminando a concessão o empresário deveria entregar o edifico a Câmara dos Vereadores em "bom estado de conservação", o documento deixava claro que na entrega o edifício deveria estar com a sua manutenção em dia ${ }^{22}$.

Diante da crise no número de habitações populares na cidade, ao longo de todo o século XIX, e do movimento menos intenso nesse mercado se comparado com o Mercado da Candelária, fez com que parte de seu edifício fosse utilizado como moradia coletiva. Desde 1892, a Prefeitura travou uma batalha judicial com os comerciantes procurando desocupar o mercado qualificado pelo prefeito como "um cortiço imundo [no qual] tudo se vendia, menos gênero de primeira necessidade", acusado de provocar muitos problemas de higiene, inclusive um caso de peste bubônica. Após idas e vindas ao Judiciário, e um incêndio que deixou o mercado "em ruínas", a Prefeitura conseguiu a suspensão do arrendamento e o despejo dos comerciantes, medidas que se concretizaram em 1900, quando o mercado foi desativado. No entanto, o mercado só desaparecia por completo em 1911 após uma longa remodelação da Praça da Harmonia iniciada pela Prefeitura em 1904, assim que as autoridades policiais recuperaram o domínio sobre essa parte da cidade durante a revolta da vacina ${ }^{23}$.

\footnotetext{
${ }^{20}$ Seidler, Carl (1980). Dez anos no Brasil, Belo Horizonte: Itatiaia, p. 66-67.

21 Regulamento da Praça do Mercado, aprovado por Portaria da Secretaria de estado dos Negócios do Império de 16 de agosto de 1844. Apud Fridman, Sergio A. \& Gorberg, Samuel (2003). Op. cit., p.14.

${ }_{22}$ Coleção das Leis do Império do Brasil (1854). Tomo XV, parte 1, p. 285-286.

${ }^{23}$ Fridman, S. A. \& Gorberg, S. (2003). Op. cit., p. 37-41.
} 
Outro mercado foi construído entre 1856-58 na freguesia da Glória onde, desde o início do século XIX, funcionava o comércio de gêneros em barraquinhas improvisadas próximo ao litoral. Sua construção foi realizada sob a responsabilidade do senhor Inácio de Barros Vieira Cajueiro, cujo contrato com a Câmara determinava que a obra deveria ser concluída em 2 anos e, em contrapartida a municipalidade oferecia "por aforamento perpétuo os terrenos de marinha existentes no local'. Além do aforamento perpétuo dos terrenos a Câmara concedeu ao construtor plenos poderes para desapropriação e demolição de imóveis que por ventura impedissem à execução das obras.

O edifício do mercado da Praça da Glória não funcionou plenamente como centro comercial, porque além de feirantes e comerciantes da pequena lavoura, gradativamente ele teria sido ocupado por famílias pobres, que precisavam morar próximo das oportunidades de trabalho. Em 1893 apenas 11 boxes do edifício eram ocupados por comerciantes com açougues, padaria e quitandas e, destes, a maioria não possuía licenças para vender seus produtos. Neste ano a Prefeitura deu uma nova função ao espaço, ocupando o edifício com o Regimento do Batalhão da Guarda Nacional, entretanto, pouco mais de um ano depois a Autoridade Sanitária, fechou o edifício justificando sua ação frente às péssimas condições sanitárias. Abandonado pelo poder público e alvo de "pessoas desocupadas que durante a noite ali fazem toda sorte de imundices e tropelias" ${ }^{24}$, o que provocou reclamações dos moradores vizinhos ao edifício, o mercado da Glória permaneceu em ruínas até 1903 quando foi demolido para "dar lugar" ao aterramento para construção da Avenida Beira Mar. A "civilização" atingia também esse ponto da cidade. No local, foi construída uma praça com um chafariz, para embelezar o caminho que ligava as freguesias centrais às regiões do eixo-sul da cidade, reduto das classes aristocráticas.

\section{De 'estômago' ao 'grande melhoramento' urbano}

A remodelação contínua de espaços da cidade com o objetivo de "reordenar" as práticas populares no comércio de alimentos não era uma experiência nova na cidade e remontam às duas últimas décadas dos Oitocentos quando tiveram início as discussões a respeito da necessidade de modernizar a Praça do Mercado da Candelária. Evidentemente, essa preocupação não estava restrita ao Mercado e fazia parte de um

\footnotetext{
${ }^{24}$ Ibidem, p. 42-46.
} 
amplo projeto de saneamento da sociedade baseado em ideias médico-higienistas que, desde meados do século XIX, orientou ações de repressão às habitações coletivas e populares, definiu a abertura de largas Avenidas, o aterramento de pântanos e o arrasamento de morros. Como chamou atenção Benchimol:

Esse discurso infiltrou-se no senso comum das camadas dominantes e das camadas médias, culturalmente subalternas, que nos anos setenta já constituíam uma influente "opinião pública", favorável a todo tipo de melhoramento que transformasse a capital do Império numa metrópole salubre e moderna ${ }^{25}$.

As freguesias centrais da cidade como a de São José, Santa Rita, Candelária - onde se incluía o Morro do Castelo - tiveram um crescimento vertiginoso e foram densamente habitadas por uma população pobre composta por negros libertos, migrantes e imigrantes em sua maioria trabalhando no comércio de gêneros alimentícios, tanto como ambulantes quanto no entorno do mercado mais importante da cidade. Certamente essa gente pobre que morava nas freguesias centrais fazia uso do mercado não só em busca de oportunidades de trabalho, mas, também, para as compras a preços mais próximos da realidade difícil que enfrentavam. A Praça do Mercado da Candelária consolidou-se como um importante lugar de compra e venda de alimentos variados, onde se desenvolviam sociabilidades também diversas, e foi justamente a variedade de pessoas, classes sociais e costumes em seu interior e entorno o que chamou atenção de um cronista:

Há grande concorrência e movimento de povo não só no recinto do mercado como também na Praça das Marinhas, e a mistura das diferentes classes da população, a desordem que parece haver entre vendedores e compradores, a reunião de homens, mulheres, meninos e escravos que ou se recreiam ou vem em busca da variedade de produtos que aí se encontram é um espetáculo curioso e característico dos costumes do país ${ }^{26}$.

Além do intenso comércio, essa região abrigava o centro administrativo do Estado e o terminal de embarque e desembarque de passageiros, por onde circulavam pessoas dos mais diversos pontos da cidade e mesmo da província. As obras realizadas nos trapiches, especialmente na segunda metade do século XIX, facilitaram consideravelmente a atracação de embarcações, ampliando o trânsito de passageiros e a carga e descarga de produtos para as casas de comércio, sobretudo no decorrer dos anos 1840 com o início da utilização de barcos a vapor. ${ }^{27}$ Em 1877 foram concluídas as obras entre a ponta do Arsenal da Marinha ao Largo do Paço, junto à Estação das Barcas ligando o Distrito Federal a Niterói, obra considerada "importante [para o] desembarque

\footnotetext{
${ }^{25}$ Benchimol, J. L. (1990). Op. cit., p. 118.

${ }^{26}$ Azevedo, M. (1877). Op. cit., p. 322-323.

27 Lamarão, Sérgio Tadeu de Niemeyer (1991). Dos trapiches ao porto: um estudo sobre a área portuária do Rio de Janeiro, Rio de Janeiro: Secretaria Municipal de Cultura, Turismo e Esportes, Departamento Geral de Documentação e Informação Cultural, Divisão de Editoração, p. 40-44.
} 
de legumes e outros gêneros alimentícios e mercadorias comercializadas no Mercado" ${ }^{28}$. Aterros, rampas e escadas tornaram mais intensa a "mistura" que incomodava a Azevedo em sua memória. A circulação de trabalhadores, vendedores, escravos de ganho, viajantes, políticos, senhores que vinham à Corte fazer negócios ou buscar apoio político, indicam que essa região não era apenas um lugar de relações comerciais variadas, mas também de encontros e trocas sociais diversas e intensas.

Nesse sentido, o estabelecimento de um lugar fixo para centralizar a venda de produtos alimentícios foi muito importante tanto para a consolidação do controle fiscal e sanitário sobre esses comerciantes quanto como tentativa de alterar as demais relações e trocas entre os diversos extratos sociais. Não que o comércio de alimentos pelas ruas tenha deixado de existir, mas as fotografias e postais que registram o interior dessas Praças de Mercado oferecem indícios de que a centralização dos comerciantes no interior das Praças de Mercados fortaleceu esses laços e dinamizou as oportunidades de socialização entre carregadores, produtores rurais, vendedores ambulantes, varredores, barqueiros. Esses vendedores que transportavam seus produtos em cestos, junto levavam notícias e fatos da região central da cidade e traziam para o Mercado informações sobre as situações ouvidas e vistas nas ruas das freguesias mais internas da cidade. Em seu ir e vir pela cidade espalhavam pelas soleiras das casas e vielas as novidades recebidas nos corredores e nas quitandas, açougues e casas de pasto do Mercado.

Podemos supor que durante a negociação com os vendedores, as criadas que ali iam realizar compras em nome de seus patrões pudessem comentar sobre dificuldades financeiras das famílias, o que não seria tão improvável diante da carestia. Ou, ainda, revelar os segredos mais íntimos da casa dos patrões que podiam ser expostos entre bancas de pescado e legumes, compartilhados com os vendedores ou mesmo com outras criadas e escravas, que também iam às compras no mercado ${ }^{29}$.

Alguns testemunhos permitem visualizar o movimento intenso dentro e em torno do Mercado da Candelária desde "antes das seis horas [quando] já é uma babel ruidosa,

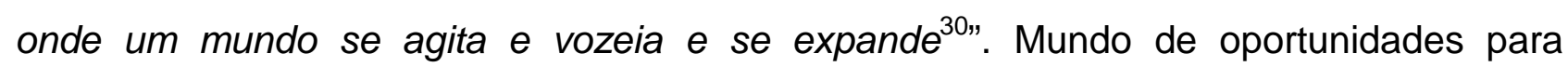
vendedores e compradores, escravos de ganho, prostitutas ${ }^{31}$, carregadores, gatunos, imigrantes pobres em busca de trabalho, libertos, criadas, catadores pobres dos morros

\footnotetext{
${ }^{28}$ Ibidem, p. 60.

29 Graham, Sandra Lauderdale (1992). Proteção e obediência: criadas e seus patrões no Rio de Janeiro, 1860-1910, São Paulo: Companhia das Letras.

${ }^{30}$ Edmundo, Luís (1957). O Rio de Janeiro de meu tempo, Rio de Janeiro: Editora Conquista, p. 60.

${ }^{31}$ Figari, Carlos (2007). As outras cariocas. Interpolações e identidades homoeróticas no Rio de Janeiro. Século XVII a XX, Belo Horizonte: Editora UFMG/Rio de Janeiro: Editora da IUPERJ, p. 108-110.
} 
da região central, que se acotovelavam nos corredores apinhados de gente. As Praças de Mercado ofereciam uma variada gama de oportunidades de sobrevivência, frente à realidade excludente que se consolidava diante das mudanças sócio econômicas da segunda metade do século.

Agregando tantas diferenças e ocupando um espaço privilegiado no centro da cidade o Mercado da Candelária também não escapou às intervenções saneadoras. Apresentando como justificativa o "crescimento da população" e do "movimento comercial' da mesma ${ }^{32}$, a Câmara Municipal autorizou o prefeito, em 1899, a realizar os entendimentos necessários com os novos arrendatários do Mercado da candelária visando sua ampliação. Entretanto, uma série de incêndios, um tanto suspeitos, ocorridos nos dias 30 de abril, 10 e 18 de julho desse ano destruíram grande parte do Mercado da Candelária $^{33}$, e levaram a administração Municipal a optar pela construção de um novo edifício, moderno e mais amplo em um local próximo. A partir daí, a municipalidade inicia um longo período de negociações com o Governo Federal para que o terreno proveniente do aterro realizado anos antes na Praia Dom Manoel fosse trocado pelo local onde, há poucos metros, estava localizado o Mercado da Candelária.

Os arrendatários do Mercado da Candelária - um grupo de empresários que incluía João Franklin de Alencar Lima, o comendador José Martins Rollo e o Coronel Theodulo Pupo de Moraes - associaram-se aos concessionários do futuro mercado em 1902 e juntos constituíram a Companhia Mercado Municipal do Rio de Janeiro para apresentar proposta à Prefeitura para construção e arrendamento da Praça do Novo Mercado ${ }^{34}$. As obras foram iniciadas em 23 de junho de 1903 e a inauguração do Mercado Municipal da Cidade do Rio de Janeiro, também chamado de Mercado Central, aconteceu em 14 de dezembro de 1907. Uma crônica de João do Rio, publicada por ocasião da mudança para o "novo" mercado, permite avaliar como essas mudanças poderiam afetar o cotidiano de muitos moradores e, particularmente, dos que sobreviviam desse comércio:

\section{Acabou de mudar-se ontem a praça do Mercado. Naquele abafado e sombrio dia de ontem era um correr de carregadores, carroças e carrinhos de mão pelos squares rentes ao Pharoux levando as mercadorias da velha praça abandonada para a nova instalação catita do largo do Moura e, ao passo que aí uma vida ainda desnorteada estridulava e enchia de ruído o silêncio do sinistro largo, na alegre e bonacheirona praça ia uma desolação de abandono, com as casas fechadas e 0 arrastar de utensílios para o meio das ruas sujas. Aquela mudança era, entretanto,}

\footnotetext{
32 Mercado da Praia de D. Manoel 1897-1903. AGCRJ. Códice 61.2.34.

${ }^{33}$ As investigações policiais iniciadas após o primeiro incêndio concluíram que o principal acusado, Pedro Lemma Perez, denunciado pelo próprio sobrinho, era inocente. O advogado encarregado da defesa desqualificou os depoimentos apresentados pela acusação uma vez que as testemunhas teriam sido pagas para resolver ali, no tribunal, uma desavença entre parentes. Ver: Peres, Pedro Lema (1900). Causa Célebre: $O$ incêndio do Mercado, Rio de Janeiro: Typ. Leuzinger, p. 3-15.

34 Mercado da Candelária, 1890-1898. AGCRJ. Códice 61.3.1.
} 
maior do que todas, era uma operação da cirurgia urbana, era para modificar inteiramente o Rio de outrora, a mobilização do próprio estômago da cidade para outro local ${ }^{35}$.

O Rio, com o esforço para deixar de ser uma cidade exótica, colonial e com "tantas tradições" no dizer de João do Rio, "foi-se delas se despojando com indiferença". "De súbito, da noite para o dia", seus moradores foram confrontados com sonhos de "ser tal qual Buenos Aires, que é o esforço despedaçante de ser Paris, e ruíram casas e estalaram igrejas, e desapareceram ruas e até ao mar se puseram barreiras". Esse tom de melancolia unida a certo descontentamento e leve crítica norteia toda a narração de João do Rio sobre o fim do Velho Mercado.

Podemos através de crônicas e imagens visualizar outras pessoas e usos dentro do mercado, alguns destes combatidos pela fiscalização ou policiamento. João do Rio nos permite entrever alguns dos usuários do "velho estômago" da cidade, acompanhar o sentimento daqueles que faziam usos diversos do Mercado da Candelária ou dele dependiam para sobreviver.

Na Praça havia a abundância, a riqueza, a miséria e a vagabundagem. Ao lado de rapazolas que mourejavam desde pela madrugada entre montanhas de vegetais $e$ ruínas sangrentas de carne, rastejando por entre as fortunas feitas às braçadas no desencaixotar das cebolas e dos alhos, viviam e morriam com fome garotos esquálidos, vagabundos estranhos, toda a vasa do crime, do horror da prostituição $(\ldots)^{36}$.

Mesmo deixando claro o seu preconceito, o cronista nos permite identificar que os mercados eram muito mais que espaços de compra e venda de alimentos, constituindo um canto "separado da cidade" onde conviviam, não sem tensões, a pobreza e a riqueza, além de prostitutas que, entre postas de bacalhau e fardos de farinha, ofereciam seu próprio corpo para consumo. Neles ocorreria toda sorte de "promiscuidades" ou ilegalidades, como o consumo de ópio que, ao cair da noite, aconteciam entre "montanhas de vegetais" e "carnes sangrentas".

Outra crônica de João do Rio dá conta de outros personagens e relações ali estabelecidos como, por exemplo, malandros, ciganos, mendigos e trabalhadores pobres que não conseguiam mais trabalhar por algum tipo de problema de saúde. Em meio a essa "Babel ruidosa", na beleza caótica do "céu, muito azuP' e do sol "derramando toda a sua luz dourada"; entre lanchas, velas brancas, ilhas, fortificações e ruas movimentadas que desembocam no cais, "a vida tumultuária da cidade vibrava num rumor de apoteose,

\footnotetext{
35 Rio, João do (1909). "O Velho Mercado". Gazeta de Notícias, Rio de Janeiro, 12 de janeiro de 1908, p. 1. Posteriormente foi incluída no livro de crônicas: Cinematographo: crônicas cariocas (1909). Porto: Lello \& Irmão.

${ }^{36}$ Rio, João do. "O Velho Mercado". Gazeta de Notícias, Rio de Janeiro, 12 de janeiro de 1908, p. 1.
} 
e era ainda mais intensa, mais brutal, mais gritada, naquele trecho do Mercado, naquele pedaço da rampa, viscoso de imundícies e de vícios" 37.

Não se pode perder de vista que as incursões de João do Rio pelo que ele próprio definiu como o lado "viscoso de imundícies e de vícios" da Capital Federal, reproduzia uma prática que era quase "lei" entre os colegas jornalistas franceses: guiar a "gente chique" com segurança pelos "lugares macabros" revelando vivências que essa sociedade fingia desconhecer. O objetivo do autor era levar seus leitores à excitante e trágica visão "que a miséria tece na sombra da noite por essa misteriosa cidade".

Procurando apresentar aos leitores uma visão mais concreta, João do Rio às vezes reproduz a voz desses sujeitos que encontra em suas andanças pela cidade. Um bom exemplo é quando conta sobre as reivindicações de estivadores, quase sempre "os pobres estrangeiros" obrigados a buscar o sustendo, afinal era a única oportunidade que muitos possuíam, e trabalhar muito de sol a sol, por uma remuneração baixíssima ${ }^{38}$. Segundo João do Rio, um trabalhador consciente da situação afirmava: "Os senhores não sabem que este país é rico, mas que se morre de fome? (...) O capital está nas mãos de grupo restrito e há gente demais absolutamente sem trabalho". E continua "os patrões não querem saber se ficamos inúteis pelo excesso de serviço". Para aquele trabalhador, era fácil encontrar ali mesmo no Mercado muitos "trabalhadores inutilizados", pelas condições ais quais foram expostos, esmolando, tendo como sustendo os restos de comida ${ }^{39}$.

A cidade apresentada por João do Rio não é somente aquela dos cafés e boutiques da Rua do Ouvidor, muito menos das confeitarias e do footing da Avenida Central. No nosso entender, mesmo diante do abismo que se criava entre as classes, de alguma forma esses "modos de vida" que aparentemente habitam mundos tão distantes, se cruzavam, no Mercado, na Igreja, nas casas de prostituição, no Bonde. Ainda que a ideia fosse excluir e afastar cada vez mais as "classes perigosas" do Centro cosmopolita da Capital Federal em alguma ocasião ou lugar - como o Mercado - essas vidas se encontravam.

Esse choque entre os usos diversos da cidade pode ser percebido justamente na Região do Mercado da Candelária, seu cais, suas bancas e a diversidade de pessoas que reunia e aproximava. Afinal, ricos e pobres, criados ou patrões precisavam comer. Ainda que para alguns as dificuldades em comprar gêneros essenciais fosse mais intensa, para

\footnotetext{
${ }^{37}$ Rio, João do (1951). "O que se vê nas ruas. Pequenas profissões". Apud A Alma encantadora das ruas, Rio de Janeiro: Organizações Simões. Esse livro é uma reunião de textos publicados entre 1904 e 1097 na Gazeta de Notícias e na revista ilustrada Kosmos.

${ }^{38}$ Rio, João do (1951). "Os Trabalhadores de Estiva". Apud A Alma encantadora das ruas, Rio de Janeiro: Organizações Simões.

39 lbidem.
} 
aqueles pobres que viviam apinhados nos cortiços das freguesias Centrais, esse comércio era, também, um espaço de oportunidades.

O escritor Luis Edmundo também nos ajuda a imaginar como se relacionavam a cidade dos ricos (moderna, cosmopolita) e a cidade dos pobres (colonial, atrasada, negra) onde "após uma boa noitada [em algum café, ou teatro ao estilo cabaré francês], o chique é comer nesse antro [o Mercado da Candelária], pela manhã ostras acompanhadas de vinho branco ${ }^{40 " . ~ A ~ R e v i s t a ~ " F o n-F o n " ~ e n d o s s a ~ o ~ q u e ~ p a r e c i a ~ s e r ~ u m a ~ p r a ́ t i c a ~ f r e q u e n t e ~}$ entre a sociedade carioca, ainda que deixe aflorar o preconceito sobre esses hábitos: "Mlle Sans Titre, Tijuca. Essa história de comer ostras de madrugada na Praça do Mercado em companhia de duas interessantes senhoritas só lhe pode ser explicado pelo próprio Figueiredo Pimentel ${ }^{41}$ ". Nas palavras de Edmundo, 'chique' e 'antro' se encontram, expressando bem sua opinião sobre o lugar. A "Praia do Peixe, ruidosa, tagarela, denunciando-se, de longe, pela enorme algazarra que levanta e pelo mau odor que exala. É um mercado digno da cidade colonial" ${ }^{42}$. A modernidade que alguns procuravam impor desde o final do século XIX chocava-se com a sociedade "colonial", particularmente com aqueles que viviam no entorno dos "estômagos da cidade".

A inauguração do Mercado Municipal em novembro de 1907 foi notícia nos jornais diários da cidade que destacaram a arquitetura toda em ferro importado de Bruxelas ocupando uma área de "22.500 metros $^{2}$ e compõe-se de um pavilhão central [destinado à venda de frutas e flores, todo envidraçado], de forma octogonal, (...) vinte e quatro pavilhões laterais (...), e quatro torreões nos ângulos, (...) contendo cada um oito compartimentos". ${ }^{43}$ Uma preocupação naquele momento era com a qualidade dos gêneros de consumo e a reportagem descreve "quatro magníficas câmaras frigoríficas destinadas à conservação de frutas, peixes e aves preparadas”. Além de apontar a modernização oferecida pelo edifício aos comerciantes e usuários do mercado, o Jornal do Brasil salienta que os materiais utilizados na construção são uma segurança diante de incêndios como aquele que, anos antes, destruiu o Mercado da Candelária. O Jornal do Comércio, por sua vez, destacou outros detalhes da construção, como a disponibilidade de sistema de água e esgoto, "sanitários ingleses dos mais aperfeiçoados" 44 , valorizando a tecnologia, materiais e equipamentos europeus empregados na construção. Desse modo, para o jornal e aqueles que investiam nos 'melhoramentos', o novo mercado estava

\footnotetext{
${ }^{40}$ Edmundo, L. (1957). Op. cit., p.59-60.

41 "Caixa de Gazolina", Revista Fon-Fon. Rio de Janeiro, n. 14, 18 de janeiro de 1908.

42 Edmundo, L. (1957). Op. cit., p.59.

43 "O Novo Mercado. Inauguração". Jornal do Brasil, Rio de Janeiro, 14 de novembro de 1907, p. 3.

44 "O Novo Mercado". Jornal do Commercio, Rio de Janeiro, 14 de dezembro de 1907, p. 3.
} 
em harmonia com a modernidade do Velho Continente. A reportagem prossegue afirmando que a nova construção "obedece a todos os preceitos da higiene moderna, é vasto, elegante: excede a todos os edifícios do mesmo gênero da América do Sul' e ainda de "algumas das mais cultas cidades do Velho Mundo" e conclui reafirmando que a obra "é sem contestação, um grande melhoramento entre os muitos de que, nos tempos recentes, tem sido dotada a Capital da República".

A imponente edificação era a maior já construída em ferro no Brasil. Inspirado especialmente no mercado parisiense Le Halles, o mercado carioca pretendia atender aos padrões de ordem e higiene que as autoridades tentavam impor à cidade. Esses novos padrões ficam evidentes no tipo de construção e materiais utilizados, na aplicação das novas tecnologias ao projeto, o que também indica a percepção do grupo de empresários da Companhia Mercado Municipal de que seria possível obter lucros proporcionais ao investimento realizado.

\section{Entre o legal e o legítimo: reivindicações e tensões no interior das praças de mercados}

A partir de 1869 o mercado da Candelária foi arrendado "por nove anos, pela Ilma. Câmara Municipal, a Aureliano Dias da Costa Cabral e ao Tenente-Coronel Antônio José da Silva [o] qual em seguida organizou uma empresa para realizar os melhoramentos [previstos no] seu contrato", a Aureliano Cabral \& C. A Câmara também determinou que os arrendatários deveriam construir o pavimento superior possibilitando seu uso como moradia ou escritório, assim como realizar obras de conservação e reparo no edifício. "Antes deste arrendamento, [o mercado] só continha o pavimento térreo, sem portas exteriores, além das dos portões das quatro faces", e tais obras de ampliação, segundo a mesma edição do Almanak Laemmert duplicaram a capacidade e melhoraram muito a aparência do Mercado da Candelária ${ }^{45}$.

Em frente ao edifício da Praça do Mercado, pelo lado do mar, a mesma empresa substituiu as barracas de lona, transformando esse espaço 'informal' "onde habitualmente faziam o seu negócio, expostos ao tempo, os roceiros que para aí traziam as suas quitandas [em] dois Chalets, que divididos em barracas, são ocupados com negócio de verduras, aves, ovos, casas de pasto, etc.". Esses melhoramentos, no entanto, que ampliaram ainda mais o Mercado e o contínuo crescimento do número de comerciantes

\footnotetext{
${ }^{45}$ Almanak Laemmert (1875). Almanak Administrativo Mercantil e Industrial do Império do Brazil. Rio de Janeiro, p. 839-840.
} 
não impediriam as tensões e disputas entre eles e deles com os arrendatários e o poder público. A razão é que para ocupar as novas barracas era "necessário solicitar uma licença e pagar uma taxa anual à Câmara" enquanto os que desejassem continuar "como antigamente, a venda de seus produtos" podiam sem "ônus algum de locação ou qualquer outro" se instalar no "espaço livre" nos "arredores do chalet erguido perto do Trapiche Maxwell'. Não tardaram a surgir descontentamentos e discordâncias, que opuseram dois grupos de negociantes e proprietários dentro da Praça das Marinhas, mais evidentes após o incêndio que destruiu dois pavilhões em abril de 1876. Em documento enviado ao Imperador um grupo de comerciantes afirmou que a "a falta de higiene e a transformação de algumas barracas em cortiços estavam condenando os chalets e concorrendo para a proliferação da febre amarela" e, por causa disso, eram contrários à sua reconstrução. No outro extremo, "mais de 70 negociantes - entre os quais 18 quitandeiras - enviaram outro abaixo-assinado à Câmara Municipal" reclamando a reconstrução dos pavilhões e alegando falta de condições adequadas para realização de seu comércio e consequente prejuízo também para o público ${ }^{46}$.

Acompanhando disputas cotidianas entre os grupos de comerciantes instalados no Mercado da Candelária, Juliana Farias analisa, em particular, a greve ocorrida em 1885, quando mais de cem pequenos lavradores, quitandeiras e pombeiros (vendedores ambulantes de peixe) paralisaram por uma semana suas atividades na Praça das Marinhas. O motivo inicial do protesto foi a discordância dos pequenos lavradores em pagar uma diária de 400 reis para o uso das "53 bancas, com armação de ferro e cobertura de lona impermeável", construídas pelos "empresários do consórcio Oliveira \& C., que arrendara o terreno à Câmara" para instalar a "feira" de legumes e hortaliças. Os manifestantes recusaram-se a vender seus produtos e impediram que barcos e carroças que vinham das freguesias suburbanas e de locais mais distantes descarregassem no cais, impedindo o funcionamento da importante praça de abastecimento de gêneros, causando um grande transtorno para os moradores da cidade e prejuízo para todos os comerciantes.

Segundo a autora, no dia 5 de outubro, data da inauguração dos "melhoramentos" para os quais o consórcio cobrou a taxa extra, uma greve já havia sido organizada e "nenhum barqueiro apareceu para oferecer legumes, aves, frutas, e outros gêneros de consumo diário". Além disso, impediram que escravos, libertos e homens livres descarregassem os produtos das canoas de ganho, saveiros e faluas que transportavam

\footnotetext{
${ }^{46}$ Farias, J. B. (2010). Op. cit., p.104-105.
} 
a produção das regiões produtoras até o Mercado. Mesmo as tentativas de fazer funcionar as bancas foram coibidas pelos grevistas, sendo necessária inclusive a presença policial para evitar maiores incidentes. $O$ impasse estendeu-se por todo o dia, mas "nada se deu" 47 .

Os grevistas "tanto [mediram] forças com empresários e vereadores, quanto [conseguiram] redefinir as formas de pressão aceitáveis na defesa de seus interesses". Os principais jornais apoiaram a greve, e os lavradores encontraram espaço para expor suas reivindicações; os manifestantes consideraram demasiadamente elevado os valores pagos como aluguel e taxa além de julgar insuficiente o espaço oferecido. Mas o aspecto mais questionado foi a legitimidade do contrato de arrendamento de 1869 que, segundo 50 mercadores, "expropriara o povo de uma área pública" - e livre da cobrança de taxas de locação pelos arrendatários - na qual desde "tempos imemoriais" se realizava a feira do mercado. O questionamento maior, portanto, foi sobre a atitude da Câmara Municipal que transformou a área de livre comércio em "possessão de empresários felizes" que passavam a lucrar com a exploração do aluguel diário das barracas. ${ }^{48}$

No dia 7 a movimentação continuou, estacas foram arrancadas de algumas barracas, e a polícia foi acionada após denuncia de que homens armados com cacetes ameaçavam aqueles que insistiam em tentar se aproximar com suas carroças cheias, vindas das regiões produtoras; porém, mesmo diante da tensão, nenhum fato mais grave foi registrado. Na manhã do dia 8, alguns vereadores foram à Praça do Mercado na tentativa de falar com os pequenos lavradores, porém não obtiveram sucesso, pela tarde "um grupo de lavradores da Penha não deixava que um só animal carregado ou qualquer carroça com legumes e verduras passasse pela ponte de Cascadura em direção à Corte". Na madrugada, 13 barraquinhas da praça das Marinhas foram inutilizadas.

No dia 09 uma marcha reuniu mais de cem quitandeiros e mercadores das freguesias suburbanas até a Rua do Ouvidor para "recorrer às folhas impressas" em busca de apoio ao movimento. Diante da redação do Diário de Notícias, o Comendador João Gomes Carneiro, representando os grevistas disse "que os pequenos lavradores não tinham como suportar 'o pesado ônus agora imposto'” ${ }^{49}$. Em outro ponto da cidade

\footnotetext{
47 Ibidem, p.106-112. Os parágrafos seguintes seguem as narrativas reunidas por esta autora sobre o movimento grevista.

${ }^{48}$ A barraca do cais da doca. Jornal do Commercio, Rio de Janeiro, 6 de outubro de 1885, p. 2. Apud Farias, J. B. (2010). Op. cit., p.106. Considerando que cada vendedor pagaria 400 réis diários e que cada barraca seria dividida com outros 5 vendedores o valor total da taxa mensal para uso de cada barraca seria de 12 mil réis, valor muito próximo ao "arrendamento de pequenas roças" pelas quais muitos pagavam cerca de 15 mil réis anuais. Idem, p. 107.

${ }^{49}$ Farias, J. B. (2010). Op. cit., p. 107.
} 
(...) pequenos agricultores de Irajá, Inhaúma e Jacarepaguá dividiram-se em dois grupos: enquanto um, (...) impedia a passagem de cargueiros e carroças que se dirigiam para a estação de trem da região; o outro, (...) armados de cassetetes proibia que os carregadores recebessem os carretos de cestos de hortaliças ${ }^{50}$.

Porém, foi nas proximidades do Largo do Pedregulho que os embates ocorreram de forma mais violenta com cerca de 100 homens armados com revolveres, punhais, foices e cacetes, que também tentavam impedir que carregamentos vindos de Inhaúma chegassem ao seu destino. O conflito foi inevitável após a chegada da polícia, e o saldo foi soldados e grevistas feridos e 17 prisões.

Com o apoio da imprensa, o Ministro do Império Ambrósio Leitão da Cunha, ordenou que a os contratos fossem suspensos e também a armação das barracas até que toda a situação fosse resolvida. Diante de tamanha repercussão, no dia 12 de outubro o imperador ordenou, por intermédio do Ministro do Império que os vereadores "designassem um local no litoral em que os referidos comerciantes possam expor à venda os seus produtos sem os vexames a que se sujeitou a concessão". A medida acalmou os pequenos lavradores, que suspenderam os protestos.

Examinando notícias, crônicas e ilustrações publicadas em revistas e jornais e também os debates travados pelos vereadores, os abaixo-assinados e as licenças enviados à Câmara Municipal, Juliana Farias acompanha o desenrolar da greve, revela quem eram os sujeitos envolvidos no movimento - indagando sobre suas motivações e articulações - e, também, procura respostas para a repercussão da greve e os apoios que conseguiu reunir na cidade. Segundo ela, alguns daqueles lavradores estavam ali desde 1870 e, através da análise das licenças concedidas pela municipalidade para as bancas de pequena lavoura, ela conseguiu reconstituir o perfil social dos grevistas. A maioria era composta por moradores da região de Niterói, e dos subúrbios do município neutro (Inhaúma, Irajá, Ilha do Governador, Engenho Novo). Levavam uma vida simples, algumas vezes estavam "instalados em terras alheias" cultivavam "hortas e roças de mandioca, café, laranjas, limão, quase sempre atendendo a demanda do mercado do Rio de Janeiro" 51 . A pesquisa nos 17 códices sobre o Mercado da Candelária, existentes no Arquivo Geral da Cidade do Rio de Janeiro, e nas listas de mercadores da praça publicadas anualmente no Almanak Laemmert entre o período de 1844 e 1889, ela verificou que, durante mais de vinte anos, todo um corredor do mercado estava ocupado por homens e mulheres da Costa da Mina. Porém, quando a greve ocorreu em 1885, já não existiam "tantos africanos assim no Rio de Janeiro e as quitandas há muito já

\footnotetext{
50 Ibidem.

51 lbidem, p.24.
} 
estavam ocupadas por seus descendentes e também por trabalhadores brancos, especialmente os imigrantes portugueses" 52.

Antes da "greve dos legumes", uma interpretação sobre a paralisação dos produtores construída pela imprensa, outro movimento de contestação ao contrato firmado entre a Câmara dos Vereadores e Arrendatários já havia mobilizado os mercadores da Praça da Candelária, em 1878. Na ocasião, comerciantes chegaram a encaminhar um requerimento ao Imperador pedido o cancelamento do arrendamento classificando-o como "vexatório e opressivo monopólio ${ }^{53 "}$. Segundo eles, o contrato lesava os cofres públicos, além de atingir seus direitos, os interesses do Estado e do público em geral.

Por trás da "denúncia" encaminhada por parte dos comerciantes estava o descontentamento diante do reajuste de $50 \%$ no preço do aluguel das bancas da Praça do Mercado, cobrado pelos arrendatários do mercado. Além disso, questionavam a possibilidade dos arrendatários obterem a prorrogação, por mais nove anos, do contrato de administração do mercado "que lhes tem resultado tão fabulosos benefícios, sem sacrifício nem trabalho" ${ }^{54}$. Sendo mais claros nesse ponto, os comerciantes chegam a relatar que "desde 1869 até hoje" não foi feita nenhuma manutenção no edifício e afirmam que suas instalações, a pintura, o chafariz, os portões estavam arruinados ${ }^{55}$. Ou seja, os negociantes acusaram os arrendatários do Mercado de descumprir um ponto importante estabelecido no contrato de concessão, pois não investiam na manutenção do edifício, explorando apenas os valores dos aluguéis, inclusive impondo um reajuste de $50 \%$, sem que a manutenção mínima fosse realizada. Qualquer semelhança com nossas concessionárias de hoje é mera coincidência.

Outras tensões podem ser vislumbradas acompanhando os modos como diferentes sujeitos utilizaram os regulamentos dos Mercados da Candelária e Municipal para encaminhar reivindicações ou protestos aos poderes executivo e legislativo. Lidamos com esse conjunto de ordenações não apenas como um dos instrumentos utilizados para regular as práticas sociais constituídas entre os diferentes grupos envolvidos com a compra e venda de alimentos, mas, principalmente, procurando sinais de que elas também geraram expectativas de direitos e serviram para mediar as relações com a administração pública dos mercados. Inicialmente procuramos reconhecer aproximações

\footnotetext{
52 Ibidem, p.140.

53 Silva, Antonio José (1877). A prorrogação do arredamento da Praça do Mercado e Chalets, Rio de Janeiro, Typ. do Apostolo, p. 3.

${ }^{54}$ Ibidem, p.8.

${ }^{55}$ Ibidem.
} 
e diferenças entre as normas definidas para o funcionamento dos dois maiores mercados da cidade, para identificar quais os direitos e deveres que os regulamentos reconheceram e observar quais as esferas do cotidiano e das relações sociais que eles procuraram normatizar. Nessa direção, um aspecto que procuramos observar foi quais as dimensões do trabalho e das relações constituídos no interior dos mercados foram objeto de maior atenção por parte da Câmara Municipal. Ou seja, tentamos perceber se os regulamentos para os Mercados expressaram uma tentativa de disciplinar com maior rigidez algumas relações, verificando indícios de criminalização de práticas, por meio da atenção às penalidades estabelecidas.

No caso do Mercado da Candelária o Regulamento foi aprovado mais de três anos após o início de seu funcionamento através de Portaria da Secretaria de Estado dos Negócios do Império e do por edital da Câmara Municipal publicado em 20 de agosto de 1844. Já o Regulamento do Mercado Municipal do Largo do Moura, foi aprovado pela Câmara dos Vereadores aos 11 de janeiro de 1908, nos primeiros dias após os comerciantes se mudarem para a nova praça de mercado. $O$ primeiro aspecto que chama a atenção é que o regulamento do Mercado da Candelária é composto por 39 artigos enquanto que o do Mercado Municipal possuía apenas 6 artigos.

Observando os temas e argumentos que compõem os artigos do Regulamento da Candelária nota-se que uma das primeiras preocupações da Câmara foi estabelecer regras para a venda de peixe fresco, tentando impedir a prática de revenda àqueles que não eram arrendatários de bancas dentro e fora da Praça. Com essa intenção o Art. $3^{\circ}$ "proíbe a revenda do peixe dentro e fora da Praça do Mercado aos que não forem consignatários das bancas ou consignatários dos pescadores", evidenciando o interesse em controlar não somente a qualidade do produto mas, também, a possibilidade de um determinado grupo monopolizar o comércio de pescado na cidade. Os dois regulamentos estabeleciam que a administração do Mercado deveria reservar um espaço para abrigar um fiscal do órgão de higiene, cabendo a ele a incumbência de lançar ao mar o peixe que não estivesse em condições adequadas ao consumo.

Juliana Teixeira de Souza analisou os conflitos por poder entre a Câmara Municipal e o Governo Imperial, e nos afirma que entre as infrações mais comuns cometidas pelos negociantes da cidade estava a "venda de produtos falsificados e a comercialização de gêneros em condições impróprias para o consumo" 56 . A autora nos explica que desde a

\footnotetext{
${ }^{56}$ Souza, Juliana Teixeira (2007). A autoridade municipal da Corte imperial: enfrentamentos e negociações na regulação do comércio de gêneros (1840-1889). Tese (Doutorado em História) - Universidade Estadual de Campinas, Campinas, p. 108-116.
} 
criação da Junta Central de Higiene em 1850, foram frequentes as disputas entre fiscais e médicos pela prerrogativa de definir a fiscalização dos alimentos e intervir no ordenamento da vida social da cidade.

Tamanha era a apreensão da prefeitura para com a questão do pescado em 1844 que além dos dois artigos supracitados outros quatro tratam do mesmo tema. Além de expressar, como dito anteriormente, a preocupação com a qualidade do pescado podemos notar também a importância do gênero para a alimentação dos moradores da cidade, diante da dificuldade em obter outros tipos de carne verde e da praticidade de possuir seu território margeado pelo mar. No início do século XX, ao lado da preocupação com o pescado, o regulamento do novo Mercado evidenciava o interesse em manter em fiscalização as "carnes verdes (inclusive miúdos, tripas, etc.) salgadas ou conservas, artigos de salsicharia, legumes e peixe em conserva ${ }^{57,}$, sobretudo regulando 0 funcionamento do Matadouro de Santa Cruz nas últimas décadas dos Oitocentos.

Outra preocupação da municipalidade corresponde aos locais e à forma como o comércio de alimentos poderia ser realizado. O interesse aí era manter os Mercados em ordem, sobretudo no centro da praça, e os Artigos $8^{\circ}$ e $9^{\circ}(1844)$ referem-se justamente à definição de locais adequados para a venda de cada tipo de produto visando manter a coordenação e alinhamento do Centro da Praça, e possibilitar às "pessoas que ali forem fazer compras" transitar "livre e comodamente". Outros artigos definem horários para descarregar produtos, para concretizar a venda e deixar a praça "desimpedida", modos de expor os gêneros evidenciando que o ordenamento do comercio na praça foi definido como questão primordial. Estas normas indicam, principalmente, uma expectativa de disciplinar as ações de comerciantes acostumados à oferecer e negociar livremente suas mercadorias e que, em diversas ocasiões, deram provas de sua aversão à delimitação de seu espaço de trabalho e à imposição de regras restritivas à sua circulação. Outro conjunto de artigos do regulamento de 1844 define normas específicas para os cuidados com a limpeza das bancas que deveriam estar "sempre no melhor asseio possível", estabelecendo varrições e lavagem de pisos e o uso de paredes, portais e outros. Há, inclusive, um artigo que regula o uso do chafariz existente no centro da Praça e a retirada das águas do mesmo também expressam essa preocupação com asseio e organização.

Outras regras miravam especialmente a "segurança pública" e as oportunidades de convivência e ajuntamentos proporcionadas pelas Praças de mercado. Assim o artigo $31^{\circ}$ proibe "andarem pretos de ganho dentro da Praça, e os escravos que ali forem mandados

\footnotetext{
${ }^{57}$ Regulamento da Praça do Mercado Municipal (1908). Boletim da Prefeitura, Circulares, Editais. AGCRJ, 11/01/1908. Art. 4ํํ․
} 
por seus senhores fazer compras, não deverão se demorar além do tempo necessário para efetua-las", indicando o temor de que a ida ao mercado facilitasse a organização dos cativos, o receio de que informações fossem trocadas e que as camadas mais pobres pudessem se organizar contra as desigualdades e opressões.

$\mathrm{Na}$ mesma direção o artigo 30 estabelecia que "ninguém poderá pernoitar nas bancas e casas" do mercado, a não ser "os locatários, seus sócios, caixeiros ou escravos, sendo responsáveis os amos pelos caixeiros e os senhores pelos escravos". Mesmo assim, estavam obrigados a informar por escrito aos fiscais uma lista dos que ali pernoitavam, ameaçando os infratores com a força armada e incursão no Código Penal. Havia previsão de que guardas municipais deveriam "pernoitar dentro da Praça" para garantir o fechamento dos portões no horário previsto e mantê-lo fechado até a alvorada. É mais uma evidência da intenção de controlar o acesso e ajuntamento noturno de trabalhadores livres ou escravos, já que dificilmente um locatário precisaria pernoitar no recinto.

No entanto, uma denuncia encaminhada por alguns dos trabalhadores do Mercado à Diretoria Central de Higiene e publicada em 25 de agosto de 1901 pelo Correio da Manhã, um jornal de grande circulação da cidade, nos ajuda a compreender melhor não apenas as condições às quais estavam submetidos aqueles trabalhadores que dormiam no mercado mas, principalmente, o uso que eles fizeram das leis e regulamentos municipais que, a princípio, serviriam apenas para regular o comércio dentro e fora do mercado. $\mathrm{Na}$ carta publicada pelo Correio da Manhã os trabalhadores denunciam:

É triste, degradante, nojento o lugar onde dormem os empregados dos comerciantes nesta praça.

Nunca a higiene pensou em dar providencias; no entanto, é conhecida por ela a grande imundice que existe neste mercado publico.

Mas não é só a higiene a quem apontamos a culpa, é ao carrancismo e à ambição que imperam sobre nós, míseros fatores da fortuna dos comerciantes, estes que sem escrúpulo nos obrigam a pernoitar nas infectas e porcas habitações, e até parece incrível que talvez 300 pessoas sejam os habitantes noturnos do grande e imundo mercado.

Estas habitações não têm ar nem luz; o ambiente que respiramos é pestífero, e especializaremos as casas que vendem aves, que são as mais nojentas, pois até criam porcos, o que é contra as posturas municipais. As lavagens destes bichos são despejadas no meio da praça, a horas que os guardas da intendência já dormem a sono solto, e mesmo que não dormissem seria o mesmo.

Se não estivéssemos na estação fria, certo teríamos o desenvolvimento de epidemias perigosas, pois estamos num verdadeiro foco.

Queremos poupar as vidas que transitam diariamente por estes sítios e as nossas, pois somos obrigados a morar em cubículos, enquanto os nossos amos e senhores vivem em sumptuosas casas, com todo o conforto higiênico, deixandonos a mercê da porcaria que em seus estabelecimentos existe.

É indecoroso, e na vossa proteção confiamos, esperando que pelas colunas do vosso jornal nos auxilieis, pedindo também aos Srs. Diretores da Higiene para ampliar suas vistas sobre a saúde de tantas vidas, que de momento a momento perigam, e sobre tudo mais é necessário e urgente providenciar afim de que se 
acabe com os dormitórios dentro da praça, pois que é contra todos os preceitos da higiene ${ }^{58}$.

Não só os trabalhadores invocaram as Posturas Municipais e os repetidos "preceitos da higiene" quanto cobraram a ação dos doutores da Diretoria de Higiene para cuidar da "saúde de tantas vidas" em risco. A situação descrita pelos trabalhadores da Praça do Mercado da Candelária é muito diversa da imagem positiva que os regulamentos e relatórios dos fiscais querem fazer crer. Toda a sujeira e o elevado número de pessoas que pernoitavam (cerca de 300 pessoas) naquela Praça certamente eram um indício do quanto o Mercado estava longe do que o Regulamento estabelecia.

Esse afastamento dos ordenamentos foi explicado pelos próprios trabalhadores, que iniciam a carta-denúncia alertando aos leitores a respeito da ganância dos locatários, que submentem aos seus empregados a lugares "sem ar e sem luz" e a situação de insalubridade era ainda mais caótica nos estabelecimentos que comercializavam animais (aves e porcos). Outro fator destacado por eles é a omissão dos Fiscais da Prefeitura responsáveis pela verificação do cumprimento das normas e, que, segundo os trabalhadores, faziam vista grossa a essas transgressões.

O interessante nessa carta é percebermos como esses empregados utilizaram as leis, o código de posturas e também a imprensa diária - e sua força de pressão sobre as autoridades - a seu favor, para reivindicar melhores condições de trabalho e habitação. Conscientes da sua condição comparam-na à dos patrões afinal, eram "obrigados a morar em cubículos", diferentemente dos "amos e senhores [que] vivem em sumptuosas casas", desfrutando do conforto e higiene, enquanto aos mais pobres restava a "porcaria", os riscos de doenças infecciosas, a peste. Chegam, inclusive, a sugerir "aos Srs. Diretores da Higiene para ampliar suas vistas sobre a saúde de tantas vidas" que corriam perigo, exigindo com urgência que "se acabe com os dormitórios dentro da praça, pois que é contra todos os preceitos da higiene".

Mais interessante é acompanhar os desdobramentos provocados pela carta enviada ao prefeito, que cobrou explicações do Diretor da Higiene, que encaminhou o recorte do jornal ao chefe do Distrito Fiscal da Candelária, o senhor Paulino Werneck. Este, por sua vez, em 30 de agosto do mesmo ano, respondeu aos seus superiores:

Informando sobre o local, junto do "Correio da Manhã" - devo dizer: Que o local destinado ao domicilio dos empregados da Praça do Mercado da Candelária apresenta boas condições de higiene - que é sabido - que o fim para que for destinado o Mercado se acha adulterado, conforme fiz sentir em documento publico que as casas que fazem o comércio de aves não tem domicílios para os empregados - que os porcos que existem no Mercado, onde alias, não são

\footnotetext{
${ }^{58}$ Mercado da Candelária, 1899-1908. AGCRJ, Códice 61.3.3. pp. 21 - 23.
} 
criados, são leitões de pequeno porte apresentando o peso máximo de 8 kilos e para isso se legalmente licenciados os comerciantes d'esse gênero de negocio que os dormitórios existentes na Praça do Mercado datam de longo tempo, pois o regulamento da Praça do Mercado, aprovado pela Lei de 20 de Agosto de 1844 concede o domicilio dos locatários e empregados dentro do estabelecimento do Mercado (art. 30) e determina que esse estabelecimento seja fechado às 8 horas da noite e aberto somente no dia seguinte às 5 horas da manhã. Parece-me que 0 cumprimento exato desta determinação tem motivado desgosto aos empregados aludidos que se sentem feridos em seus direitos. É o que cabe-me informar a respeito.

Talvez o fiscal do Mercado tivesse coisas mais importantes a verificar do que checar denuncias de trabalhadores pobres. Vale lembrar que o Regulamento do Mercado estabelecia que no boxe de número 31 da Praça funcionaria a residência de Guardas Municipais designados pelo Fiscal responsável pelo serviço no Mercado. A esses guardas, como cita o fiscal Paulino Werneck, cabia verificar o nome e número de pessoas que dormiam no interior do mercado e supervisionar a limpeza diária no final do funcionamento das atividades. O que nos permite levantar outras questões: talvez as desavenças entre esses trabalhadores e os encarregados de manter a lei e a ordem dentro do mercado já viessem de mais tempo e envolvessem também os guardas da intendência que dormiam dentro do mercado "a sono solto" segundo os denunciantes. Além disso, eles afirmam que "mesmo que não dormissem seria o mesmo", ou seja, os guardas nada fariam para cumprir o regulamento já que isso significaria colocar limites às atividades dos comerciantes. Após as denuncias, o Prefeito encaminhou à Diretoria de Obras e Viação para que fossem realizadas obras no pátio do Mercado com o objetivo de melhorar as condições de higiene e asseio. O processo foi arquivado e somente com a construção do novo mercado os trabalhadores poderiam ter esperanças quanto à melhorias em seu local de pernoite.

Quem sabe por conta de denúncias e situações como essas, o Regulamento da nova Praça do Mercado aprovado em 1908 estabeleceu em seu Art. $2^{\circ}$ que "Ninguém poderá pernoitar no interior da praça e nos negócios, a não serem o porteiro e os vigias" 59. Além de evitar qualquer brecha para novas disputas entre patrões e trabalhadores no mercado, podemos especular sobre uma preocupação também moral. Afinal o Mercado da Candelária era conhecido como lugar propício à prostituição, às "promiscuidades" de todo tipo e onde o "caos e a desordem" encontravam terreno fértil. A restrição significativa no horário de funcionamento da Praça é outro indício dessa preocupação ou de, pelo menos, manter as aparências:

\footnotetext{
${ }^{59}$ Regulamento da Praça do Mercado Municipal (1908). Op. cit.. Editais de 11/01/1908.
} 
Art. $1^{\circ}$ - A Praça do Mercado abrirá diariamente às 4 horas da manhã e fechar-seá às 8 horas da noite, com exceção dos compartimentos com frente para a parte externa do edifício, que poderão ficar abertas até às 10 horas da noite, a juízo do Prefeito, desde que não tenham comunicação para o interior da Praça.

Entretanto, um requerimento de um grupo de Locatários que tinham portas voltadas para o interior do edifício mobilizou-se para conseguir reverter esse artigo, pois todos os comerciantes estabelecidos no mercado reivindicavam o direito de abrir e fechar seus estabelecimentos no mesmo horário. Os comerciantes alegaram que a imposição de fechar às 8 horas da noite, lesava os seus interesses e causava prejuízo em suas vendas. Em documento, com data de 08 de janeiro de 1908, o prefeito encaminha, e endossa a solicitação dos comerciantes à Câmara:

\section{Exmo Srs.}

O artigo 1 , das instruções dadas em 23 de dezembro passado (1907) para a nova Praça do Mercado, estitui que a mesma Praça se fechará às 6 horas da tarde nos meses de outubro a março e às 5 horas nos outros meses do ano. Ora, sendo considerados como pertencentes à Praça do Mercado os compartimentos que têm entrada pelas ruas externas, segue-se que a todos eles abrange a prescrição da hora para fechamento de portas.

Alegam comerciantes interessados na questão que não parece justo equiparar em tudo os compartimentos que abrem para o exterior aos que abrem para as suas externas, nenhum inconveniente haveria, dizem eles, em permitir que os primeiros se fechassem mais tarde, de acordo com as posturas gerais da cidade. - e esta faculdade dar-lhes ia margem para maior soma de negócios.

Claro está que a referida licença não implicaria revogar nem modificar o artigo $2^{\circ}$ das mesmas instruções, que proíbe a quem quer que seja pernoitar no interior da Praça e nos negócios, exceto o porteiro e os vigias.

Representantes do comercio importador de vinhos e outras bebidas solicitam igualmente de V.Ex. que seja permitido na Praça o comercio destes artigos, cuja eliminação absoluta constituiria uma desigualdade, prejudicando notoriamente a sua numerosa clientela.

Tendo a honra de transmitir a V.Ex. estes pedidos, a Associação espera do alto critério de V.Ex. uma decisão equitativa que harmonize os interesses da Praça do Mercado e o dos particulares comerciantes que ali pretendem estabelecer-se com as expressões da minha alta estima e apreço.

Exmo. Sr. Dr. Francisco Marcellino de S. Aguiar ${ }^{60}$.

O primeiro aspecto a destacar é a diferença no encaminhamento e nos termos da resposta dada pela Prefeitura às reivindicações desses comerciantes e dos trabalhadores, analisada anteriormente. Ao "transmitir" à Câmara "os pedidos" que recebeu, o prefeito habilmente vai enumerando os aspectos do regulamento recém-aprovado pelos vereadores contra os quais os comerciantes se mobilizaram - diferenciação entre boxes internos e externos, horário de funcionamento -, indicando a necessidade de uma "decisão equitativa que harmonize os interesses" em jogo. Ao encaminhar as demandas dos "representantes do comercio importador de vinhos e outras bebidas" insatisfeitos com a proibição do comércio desses produtos no interior do mercado, o prefeito ao qualificálas como "uma desigualdade" avaliza as pressões sobre a Câmara para alterar o

\footnotetext{
${ }^{60}$ Mercado da Praia Dom Manoel, 1907-1914. AGCRJ, Códice 61.3.9 p.7.
} 
regulamento recém-aprovado. E ainda lembra aos vereadores que os comerciantes de bebidas alcoólicas tinham uma "numerosa clientela" que também seria prejudicada.

Ou seja, neste caso não apenas não se questiona a legitimidade da reivindicação como, ao reproduzir os argumentos dos "interessados na questão" - manter o regulamento "não parece justo" - o prefeito apóia o pleito dos comerciantes insatisfeitos, apesar de suas demandas contrariarem o regulamento recém aprovado. Nestes primeiros anos após a inauguração do Mercado Municipal da Praia D. Manoel, o comercio de bebidas alcoólicas era proibido e o regulamento não permita que o produto fosse negociado ali. E não foi ainda desta vez que os comerciantes do ramo de importação conseguiram "atender a sua clientela". A Câmara determinou que nada mudaria naqueles anos na Praça do Novo Mercado. Os comerciantes teriam que negociar muito para fazer valer seus interesses.

\section{Fontes}

\section{Arquivo Geral da Cidade do Rio de Janeiro:}

Boletim da Prefeitura, Circulares, Editais. 11/01/1908.

Códice 61.2.34 - Mercado da Praia de D. Manoel, 1897-1903.

Códice 61.3.1 - Mercado da Candelária, 1890-1898.

Códice 61.3.3 - Mercado da Candelária, 1899-1908.

Códice 61.3.9 - Mercado da Praia Dom Manoel, 1907-1914.

\section{Biblioteca Nacional:}

Coleção das Leis do Império do Brasil, 1854, Tomo XV, parte 1.

Peres, Pedro Lema. Causa Célebre: $O$ incêndio do Mercado. Rio de Janeiro: Typ. Leuzinger.1900. I - 202, 5, 15.

Silva, Antonio José. A prorrogação do arredamento da Praça do Mercado e Chalets. Rio de Janeiro, Typ. do Apostolo, 1877. II-80,1,11 n.2 .

\section{Imprensa:}

Almanak Laemmert, Almanak Administrativo Mercantil e Industrial do Império do Brazil para 1844. Rio de Janeiro.

Jornal do Commercio, edições de 14 e 15 de dezembro de 1907.

Jornal do Brasil, edições de 14 e 15 de dezembro de 1907.

Revista “Fon-Fon", n. 14, 18 de janeiro de 1908. 


\section{Memorialistas:}

Azevedo, Moreira de (1877). Rio de Janeiro: sua história, monumentos, homens notáveis, usos e curiosidades, V. 2 Rio de Janeiro: B. L. Garnier.

Costa, Nelson (1958). Rio de Ontem e de Hoje, Rio de Janeiro: Leo.

Edmundo, Luís (1957). O Rio de Janeiro de meu tempo, Rio de Janeiro: Editora Conquista.

Rio, João do. "Cinematographo", Gazeta de Notícias, 12/01/1908.

(1951). A Alma encantadora das ruas, Rio de Janeiro: Organizações Simões.

Seidler, Carl (1980). Dez anos no Brasil, Belo Horizonte: Itatiaia.

\section{Referências Bibliográficas}

Benchimol, Jaime Larry (1990). Pereira Passos: um Haussmann tropical. A renovação urbana da cidade do Rio de Janeiro no início do século $X X$, Rio de Janeiro: Secretaria Municipal de Cultura, Turismo e Esportes.

Farias, Juliana Barreto (2010). "Mercado em greve: Protesto e organização dos trabalhadores do pequeno comércio no Rio de Janeiro - Outubro, 1885". Anais da Biblioteca Nacional, v. 127.

Figari, Carlos (2007). As outras cariocas. Interpolações e identidades homoeróticas no Rio de Janeiro. Século XVII a XX, Belo Horizonte: Editora UFMG. Rio de Janeiro: Editora da IUPERJ.

Fridman, Sergio A. \& Gorberg, Samuel (2003). Mercados no Rio de Janeiro. 1834-1962, Rio de Janeiro: S. Gorberg.

Graham, Sandra L. (1992). Proteção e obediência: criadas e seus patrões no Rio de Janeiro (1860-1910), São Paulo: Companhia das Letras.

Lamarão, Sérgio Tadeu de Niemeyer (1991). Dos trapiches ao porto: um estudo sobre a área portuária do Rio de Janeiro, Rio de Janeiro: Secretaria Municipal de Cultura, Turismo e Esportes, Departamento Geral de Documentação e Informação Cultural, Divisão de Editoração.

Sampaio, Antonio Carlos Jucá de (1994). Magé na crise do escravismo. Sistema agrário e evolução econômica na produção de alimentos (1850-1888), Dissertação (Mestrado em História) - Instituto de Ciências Humanas e Filosofia, Universidade Federal Fluminense, Niterói.

Souza, Juliana Teixeira (2007). A autoridade municipal da Corte imperial: enfrentamentos e negociações na regulação do comércio de gêneros (1840-1889). Tese (Doutorado em História) - Universidade Estadual de Campinas, Campinas. 
Passagens. Revista Internacional de História Política e Cultura Jurídica,

Rio de Janeiro: vol. 4, no.1, janeiro-abril 2012, p. 55-80.

Aprovado para publicação em dezembro de 2011. 